\title{
Prognostic value of late enhancement in cardiac magnetic resonance in patients with dilated cardiomyopathy: a meta-analysis
}

\author{
Francesco Secchi', Marcello Petrini, Paola M Cannao, Marco Alì, Giovanni Di Leo, Massimo Lombardi, \\ Francesco Sardanelli
}

From 19th Annual SCMR Scientific Sessions

Los Angeles, CA, USA. 27-30 January 2016

\section{Background}

To systematically review the prognostic value of late gadolinium enhancement (LGE) at cardiac magnetic resonance (CMR) in patients with dilated cardiomyopathy (DCM).

\section{Methods}

A literature search was performed on Medline and Embase for original articles estimating the LGE prognostic value in patients with DCM. Original articles had to assess mortality for cardiac and non-cardiac causes, sudden cardiac death, sudden death avoided, and hospitalization for cardiac failure. Heterogeneity $\left(\mathrm{I}^{2}\right)$ was evaluated using the Cochrane Q statistics: P-value $<0.100$ were considered significant. Pooled odd ratio (OR) and 95\% confidence interval (CI: 95\%) were calculated using Comprehensive Meta-Analysis.

\section{Results}

Out of 691 articles initially retrieved, 6 prospective clinical trials were selected for a total of 1,017 patients. All analyzed studies were performed using a 1.5-T MR unit. LGE was positively correlated with all considered clinical outcomes. Pooled mortality for all causes showed $\left.\mathrm{I}^{2}=33 \% \mathrm{p}=0.202\right)$ and $\mathrm{OR}=2.6(95 \% \mathrm{CI} 1.7-4.0 ; p<0.001)$; hospitalization for cardiac failure showed $\mathrm{I}^{2}=24 \%$ $(p=0.257)$ and $\mathrm{OR}=2.7$ (95\%CI 1.8-4.1; $p<0.001)$; sudden cardiac death showed $\mathrm{I}^{2}=0 \%(p=0.895)$ and $\mathrm{OR}=3.2(95 \%$ CI 1.6-6.3; $p=0.001)$; death for cardiac causes showed $\mathrm{I}^{2}=0 \%(p=0.782)$ and $\mathrm{OR}=3.5(95 \% \mathrm{CI} 2.2-5.7 ; p<0.001)$; sudden death avoided showed $\mathrm{I}^{2}=0 \%(p=0.815)$ and $\mathrm{OR}=6.3$ (95\%CI 3.4-11.6; $p<0.001)$.

\section{Conclusions}

LGE at CMR in patients with CMD is closely related to a more negative prognosis if compare to patients without LGE.

Published: 27 January 2016

doi:10.1186/1532-429X-18-S1-P114

Cite this article as: Secchi et al:: Prognostic value of late enhancement in cardiac magnetic resonance in patients with dilated cardiomyopathy: a meta-analysis. Journal of Cardiovascular Magnetic Resonance 201618 (Suppl 1):P114.
Submit your next manuscript to BioMed Central and take full advantage of:

- Convenient online submission

- Thorough peer review

- No space constraints or color figure charges

- Immediate publication on acceptance

- Inclusion in PubMed, CAS, Scopus and Google Scholar

- Research which is freely available for redistribution 